\title{
Nonconvulsive Status Epilepticus During Perioperative Period of Cerebrovascular Surgery
}

\author{
Takato MORIOKA, ${ }^{1}$ Tetsuro SAYAMA, ${ }^{1}$ Nobutaka MUKAE, ${ }^{1}$ \\ Takeshi HAMAMURA, ${ }^{1}$ Kuniko YAMAMOTO, ${ }^{2}$ Tomomi KIDO, ${ }^{2}$ \\ Ayumi SAKATA, ${ }^{3}$ and Tomio SASAKI ${ }^{4}$ \\ Departments of ${ }^{1}$ Neurosurgery and ${ }^{2}$ Clinical Laboratory, \\ Kyushu Rosai Hospital, Kitakyushu, Fukuoka; \\ ${ }^{3}$ Department of Clinical Chemistry and Laboratory Medicine, \\ Kyushu University Hospital, Fukuoka; \\ ${ }^{4}$ Department of Neurosurgery, Graduate School of Medical Sciences, \\ Kyushu University, Fukuoka
}

\begin{abstract}
Nonconvulsive status epilepticus (NCSE) is generally defined as a change in behavior and/or mental process from the baseline, which is associated with ongoing seizure activity or continuous epileptiform discharges on electroencephalography (EEG) in the absence of convulsive seizures. The present study investigated NCSE incidence using serial EEG during the perioperative periods of cerebrovascular surgery at a medium-sized, local hospital. A total of 54 patients were admitted to our department and underwent various neurosurgical procedures over a course of one year. If clinical symptoms worsened without clear explanation, EEG was performed, resulting in a diagnosis of NCSE in four patients (7.4\%). The EEG abnormalities included periodic lateralized epileptiform discharges in 1 patient, triphasic waves in 2 patients, and repeated ictal discharges in 1 patient. Improved mental status and consciousness level, together with disappearance of EEG abnormalities, after appropriate anticonvulsant treatment supported the diagnosis of NCSE. The present study stressed the importance of EEG if no adequate explanation for neurological deterioration can be determined from the clinical course, laboratory data, or neuroimaging examination.
\end{abstract}

Key words: nonconvulsive status epilepticus, electroencephalography, periodic lateralized epileptiform discharge, triphasic wave, cerebrovascular surgery

\section{Introduction}

Nonconvulsive status epilepticus (NCSE) is generally defined as a deviation in behavior and/or mental process from the baseline associated with ongoing seizure activity or continuous epileptiform discharges on electroencephalography (EEG) in the absence of convulsive symptoms, although no universal definition for NCSE is accepted..$^{2,25,29)}$ Convulsive status epilepticus is easily recognized, whereas NCSE may present with discrete clinical features which are difficult to differentiate from unconsciousness and even normal behavior associated with primary central nervous system disease. Therefore, NCSE is typically overlooked and, conse-

Received September 28, 2010; Accepted December 8, 2010 quently, not properly treated.9,25,30) The incidence of convulsive status epilepticus in the population with cerebrovascular disease (CVD) remains unclear, but is estimated at $14-30 \%{ }^{8,22,28,32)}$ In contrast, the incidence of NCSE in patients with CVD is relatively unstudied. ${ }^{18,23)}$ The diagnosis of NCSE requires clinical suspicion and EEG confirmation. ${ }^{2,9,19,25,29,30)}$ NCSE should be immediately considered in patients with CVD who suffer worsening of clinical symptoms. ${ }^{29)}$

The present study investigated the incidence of NCSE through the use of serial EEG during the perioperative periods of CVD surgery. The relationships between epileptogenesis, management, and functional outcome were also evaluated.

\section{Materials and Methods}

A total of 54 patients with CVD (ruptured aneurysm 
in 6 patients, unruptured aneurysm in 7 , intracerebral hemorrhage in 13 , intracerebellar hemorrhage in 5, stenosis of internal carotid artery [ICA] in 15, occlusion of ICA or middle cerebral artery [MCA] in 3, moyamoya disease in 2, dural arteriovenous fistula [AVF] in 2, and acute cerebral infarction in 1) were admitted to our department and underwent various neurosurgical procedures between April 1, 2009 and March 31, 2010. Surgical procedures included aneurysm clipping in 13 patients, evacuation of intracerebral and cerebellar hemorrhage in 10 (6 via craniotomy, and 4 via endoscopic or stereotaxic), carotid endarterectomy (CEA) in 15, carotid stenting in 1, superficial temporal artery (STA)-MCA anastomosis in 6, decompressive craniectomy in 1, endovascular embolization of dural AVF in 2, lumbo- or ventriculoperitoneal shunt in 5 , and external ventricular drainage in 6. During the perioperative periods of these surgical procedures, any neurological deterioration, which could not be explained by the clinical course, laboratory data, or neuroradiological examination, was investigated by EEG to determine the possible presence of NCSE. Recordings were obtained from 12- or 16-channel EEGs with electrode placement according to the international $10-20$ system. Based on the diagnosis of NCSE, antiepileptic agents were administered, and the response was estimated based on clinical and EEG findings. Pathophysiological mechanisms of NCSE were also analyzed with serial EEG and neuroradiological ex- aminations. Functional outcomes were assessed at 6-12 months after surgery using the modified Rankin scale (mRS). ${ }^{31)}$

\section{Results}

Five of the 54 patients exhibited unexpected worsening of clinical symptoms during the perioperative period. Four patients (7.4\%) had diagnoses of NCSE based on serial EEG. The detailed clinical courses and EEG findings of these 4 patients are described below and summarized in Table 1 .

Case 1: A 70-year-old man was found unconscious. On admission, the patient was in a semicomatose state (Japan Coma Scale [JCS] 100). Convulsive status epilepticus was observed in the right extremities, but was controlled with intravenous diazepam administration followed by a phenytoin loading dose. Computed tomography (CT) revealed a small intracerebral hematoma at the right temporo-occipital junction, as well as disappearance of cortical sulci in the right temporo-occipital lobe (Fig. 1A). Controlled ventilation via oro-tracheal intubation was performed with a midazolam drip infusion.

Extubation was performed on day 3. The patient remained in a drowsy state and at times exhibited restless confusion. Verbal comprehension was barely possible, and aphasia was observed, as well as right hemiparesis. Magnetic resonance (MR) imaging using the fluid-attenuated inversion recovery se-

Table 1 Clinical profiles of the patients with nonconvulsive status epilepticus (NCSE)

\begin{tabular}{|c|c|c|c|c|c|c|c|c|c|}
\hline \multirow{2}{*}{$\begin{array}{l}\text { Case } \\
\text { No. }\end{array}$} & \multirow{2}{*}{$\begin{array}{l}\text { Age } \\
\text { (yrs), } \\
\text { Sex }\end{array}$} & \multirow{2}{*}{ Diagnosis } & \multirow{2}{*}{$\begin{array}{l}\text { Neurosurgical } \\
\text { procedure } \\
\text { (timing) }\end{array}$} & \multirow{2}{*}{$\begin{array}{l}\text { Onset of } \\
\text { NCSE }\end{array}$} & \multirow{2}{*}{ EEG pattern } & \multicolumn{2}{|c|}{$\begin{array}{l}\text { Possible pathophysiological } \\
\text { mechanisms of NCSE }\end{array}$} & \multirow{2}{*}{ Treatment } & \multirow{2}{*}{$\begin{array}{c}\text { Outcome } \\
\text { (mRS) } \\
\text { (pre- } \rightarrow \\
\text { post- } \\
\text { surgery) }\end{array}$} \\
\hline & & & & & & $\begin{array}{l}\text { Epileptogenic } \\
\text { area }\end{array}$ & $\begin{array}{l}\text { Additional } \\
\text { factors }\end{array}$ & & \\
\hline 1 & $70, \mathrm{M}$ & $\begin{array}{l}\text { ruptured } \\
\text { dural AVF }\end{array}$ & $\begin{array}{l}\text { embolization } \\
\text { (day 30) }\end{array}$ & $\begin{array}{c}\text { day } 3 \\
\text { after } \\
\text { ICH }\end{array}$ & PLEDs & $\begin{array}{l}\text { small ICH, } \\
\text { lt temporo- } \\
\text { occipital } \\
\text { lobe }\end{array}$ & $\begin{array}{l}\text { venous } \\
\text { congestion }\end{array}$ & $\begin{array}{l}\text { changed AED } \\
(\mathrm{PHT} \rightarrow \mathrm{CBZ})\end{array}$ & $1 \rightarrow 1$ \\
\hline \multirow[t]{2}{*}{2} & $79, \mathrm{~F}$ & $\begin{array}{l}\text { ruptured } \\
\text { AcomA } \\
\text { aneurysm }\end{array}$ & $\begin{array}{l}\text { neck clipping } \\
\text { (day 1) }\end{array}$ & $\begin{array}{r}\text { day } 16 \\
\text { after } \\
\text { SAH }\end{array}$ & $\begin{array}{l}\text { triphasic } \\
\text { waves }\end{array}$ & $\begin{array}{l}\text { acute } \\
\text { infarction, } \\
\text { rt frontal lobe }\end{array}$ & $\begin{array}{l}\text { SAH, } \\
\text { meningitis, } \\
\text { antibiotics }\end{array}$ & $\begin{array}{l}\text { changed AED } \\
(\mathrm{PHT} \rightarrow \mathrm{CBZ})\end{array}$ & $1 \rightarrow 3$ \\
\hline & & & $\begin{array}{l}\text { LP shunt (day } \\
\text { 29) }\end{array}$ & $\begin{array}{l}\text { day } 0 \\
\text { after LP } \\
\text { shunt }\end{array}$ & $\begin{array}{l}\text { triphasic } \\
\text { waves }\end{array}$ & $\begin{array}{l}\text { acute } \\
\text { infarction, } \\
\text { rt frontal lobe }\end{array}$ & $\begin{array}{l}\text { sevoflurane } \\
\text { anesthesia }\end{array}$ & $\begin{array}{l}\text { increased } \\
\text { CBZ }\end{array}$ & \\
\hline 3 & $75, \mathrm{~F}$ & $\begin{array}{l}\text { cerebellar } \\
\text { hemorrhage }\end{array}$ & $\begin{array}{l}\text { hematoma } \\
\text { evacuation } \\
\text { (day 0) }\end{array}$ & day 0 & $\begin{array}{l}\text { triphasic } \\
\text { waves }\end{array}$ & $\begin{array}{l}\text { old infarction, } \\
\text { rt frontal lobe }\end{array}$ & $\begin{array}{l}\text { hydrocephalus, } \\
\text { sevoflurane } \\
\text { anesthesia }\end{array}$ & PHT & $4 \rightarrow 4$ \\
\hline 4 & $77, \mathrm{M}$ & $\begin{array}{l}\text { MCA } \\
\text { occlusion }\end{array}$ & $\begin{array}{l}\text { STA-MCA } \\
\text { anastomosis }\end{array}$ & $\begin{array}{l}\text { day } 6 \\
\text { after } \\
\text { surgery }\end{array}$ & $\begin{array}{l}\text { frequent } \\
\text { ictal } \\
\text { discharges }\end{array}$ & $\begin{array}{l}\text { anastomosis } \\
\text { site }\end{array}$ & $\begin{array}{l}\text { hyperperfu- } \\
\text { sion }\end{array}$ & PHT & $2 \rightarrow 2$ \\
\hline
\end{tabular}

AcomA: anterior communicating artery, AED: antiepileptic drug, AVF: arteriovenous fistula, CBZ: carbamazepine, EEG: electroencephalography, F: female, ICH: intracerebral hemorrhage, LP: lumbo-peritoneal, lt: left, M: male, MCA: middle cerebral artery, mRS: modified Rankin scale, PHT: phenytoin, PLEDs: periodic lateralized epileptiform discharges, rt: right, SAH: subarachnoid hemorrhage, STA: superficial temporal artery. 

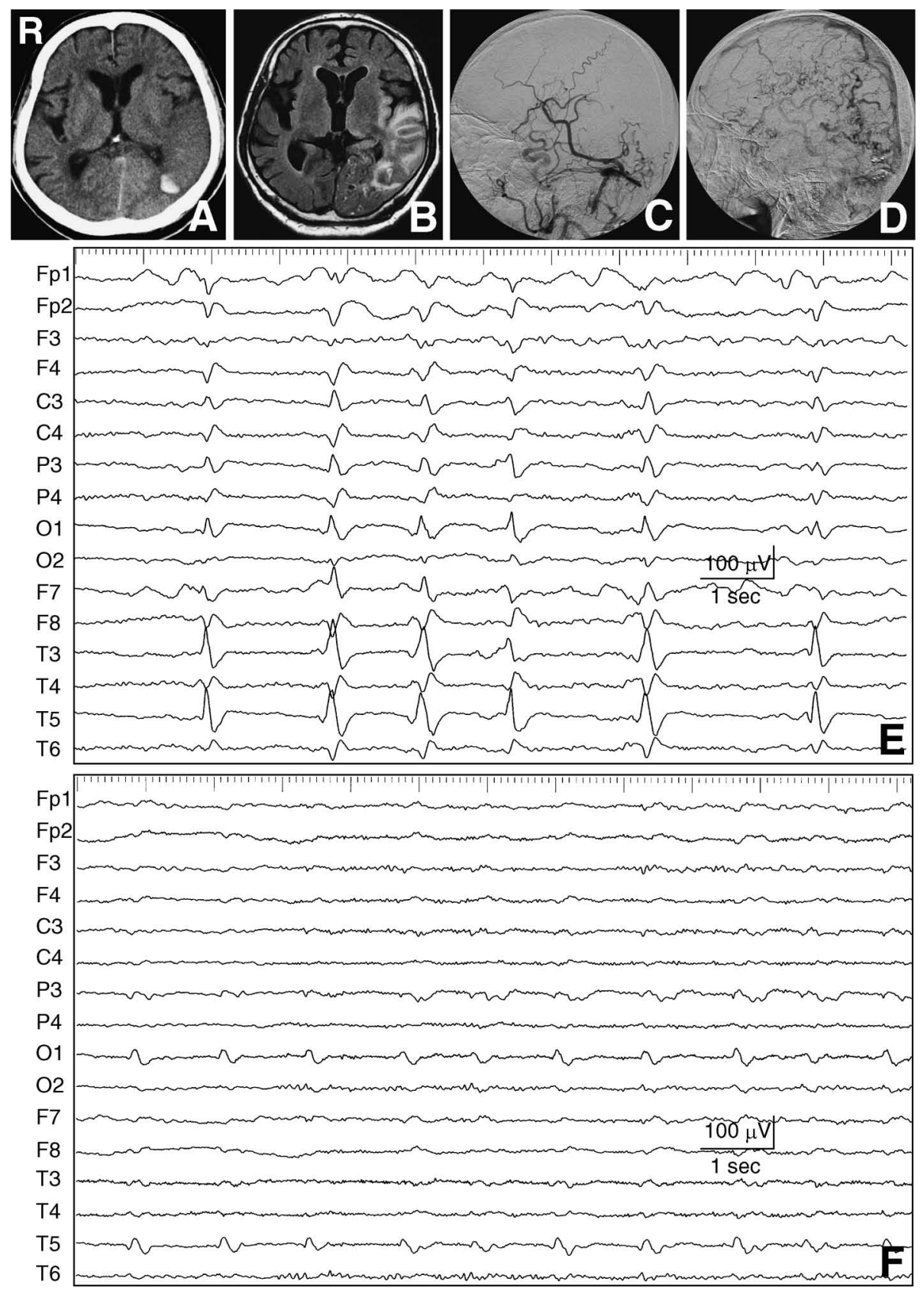

Fig. 1 Case 1. A: Computed tomography scan on admission revealing a small intracerebral hematoma at the right temporo-occipital junction and disappearance of cortical sulci in the right temporo-occipital lobe. B: Fluid-attenuated inversion recovery magnetic resonance image on day 3 demonstrating a high-intensity area around the hematoma that extends from the occipital lobe to the temporal lobe and the insular cortex. Multiple flow voids are also observed in the medial part of the left occipital lobe. C: Arterial phase of the left external carotid angiogram revealing a fistula from the left occipital artery to the left transverse sinus. D: Venous phase of the left external carotid angiogram showing prominent venous reflux on the posterior part of the left hemisphere. No obstruction or stenosis of the venous sinus is observed. E: Electroencephalogram (E EG) (averaged reference) on day 3 showing periodic lateralized epileptiform discharges (PLEDs) on the left. The highest amplitude epileptiform discharges are located in the left middle and posterior temporal region ( $\mathrm{T} 5$ of international EEG 10-20 system), which is identical to the hematoma location. F: EEG on day 11 revealing small-amplitude PLEDs. 
quence (FLAIR) demonstrated a high intensity area around the hematoma (Fig. 1B). Angiography revealed a fistula from the left occipital artery to the left transverse sinus (Fig. 1C), so the diagnosis was dural AVF. Prominent venous reflux was noted in the posterior part of the left hemisphere (Fig. 1D).

No convulsive seizures were apparent, but EEG revealed periodic lateralized epileptiform discharges (PLEDs) on the left (Fig. 1E). The highest amplitude epileptiform discharges were located in the left middle and posterior temporal region (T5 of the international EEG 10-20 system). Based on the diagnosis of NCSE, the antiepileptic agent was changed from oral phenytoin to carbamazepine. On day 11 , the patient became well-orientated, although he still displayed mild aphasia and right hemiparesis. PLED amplitudes were significantly decreased (Fig. 1F). On day 20, the patient was transferred to another hospital for endovascular embolization of the dural AVF. One year after successful embolization therapy, the patient was able to live independently, although very mild aphasia was observed (mRS 1).

Case 2: A 79-year-old woman suddenly developed severe headache. She was alert, but CT revealed subarachnoid hemorrhage (Fig. 2A) and CT angiography demonstrated a ruptured aneurysm of the anterior communicating artery (AcomA). The patient was sedated with midazolam and CT on the following day revealed re-rupture of the aneurysm (Fig. 2B). Clipping of the AcomA aneurysm was performed through the right pterional approach under general anesthesia (1-3\% sevoflurane for 8 hours). During surgery, temporal occlusion of the left $A_{1}$ for 11 minutes and the left $A_{2}$ for 5 minutes was needed to perform successful clipping.

Post-surgery, the patient was in a drowsy state (JCS 30), and CT revealed an equivocal low density area in the bilateral frontal base (Fig. 2C). Intravenous administration of edaravone and phenytoin was started. On day 3, CT revealed a low density area in the bilateral frontal lobes with intracerebral hemorrhage in the left frontal lobe (Fig. 2D). On days 9-15, antibiotics, such as meropenem and vancomycin, were systemically administered to treat post-operative meningitis. On day 13 , lumbar drainage was placed for control of progressive ventricular enlargement. Subsequently, the consciousness level of the patient was increased to JCS 2-10. However, around day 16, the patient became semicomatose. CT failed to detect any additional abnormal findings (Fig. 2E). EEG examination on day 22 revealed triphasic waves in the bilateral frontal regions, predominantly on the right (Fig. 2F). The initial negative components of the triphasic waves exhibited epileptiform morphologies with the components resembling spikes of "spike and slow wave" complexes in the right frontal region (F4 and Fp2). Based on the diagnosis of NCSE, the antiepileptic agent was changed from phenytoin to carbamazepine, and the patient gradually became alert. EEG on day 26 showed disappearance of the triphasic waves.

Lumbo-peritoneal (LP) shunting was performed under general anesthesia (1-3\% sevoflurane for 2 hours) for treatment of progressive hydrocephalus on day 29. Although the surgical procedure was uneventful and post-surgical CT revealed well-controlled ventricular size (Fig. 2G), prolonged unconsciousness following anesthesia was noted. EEG on day 35 detected the reappearance of triphasic waves in the bilateral frontal regions (Fig. 2H). The patient gradually regained consciousness with increased dose of carbamazepine. At 2 months after the initial surgery, the patient was alert and could walk with support. EEG showed disappearance of the triphasic waves. The patient was transferred to another department for further rehabilitation, and the mRS was 3 at 8 months after the initial surgery.

Case 3: A 75-year-old woman was admitted to the orthopedic ward of our hospital with a diagnosis of femoral neck fracture. The patient also had dementia and had been treated with warfarin for previous cerebral and myocardial infarctions. She had a mRS score of 4 . The patient was found unconscious on her bed in a drowsy state (JCS 30). CT revealed left cerebellar hemorrhage and obstructive hydrocephalus (Fig. 3A, B).

The patient underwent hematoma evacuation via suboccipital craniotomy, followed by external ventricular draining via the left posterior horn under general anesthesia $(0.3-0.5 \%$ sevoflurane with fentanyl for 5 hours and 15 minutes). Post-surgical CT demonstrated successful evacuation of the hematoma and well-controlled hydrocephalus (Fig. 3C), but the patient remained in a semicomatose state. EEG on day 5 revealed triphasic waves in the bilateral frontal regions, predominantly on the right (Fig. 3D). Based on the diagnosis of NCSE, phenytoin administration was started. Around day 10, the patient became alert, and FLAIR MR imaging demonstrated multiple old infarctions in the white matter of the bilateral frontal lobes, basal ganglia, and left thalamus (Fig. 3E). EEG on day 25 detected rare triphasic waves in the right frontal region, but no triphasic waves were noted on day 85. Six months after onset, the patient was alert, but dependent, due to dementia and the femoral neck fracture. The mRS values remained unchanged from before onset of cerebellar hemorrhage. 

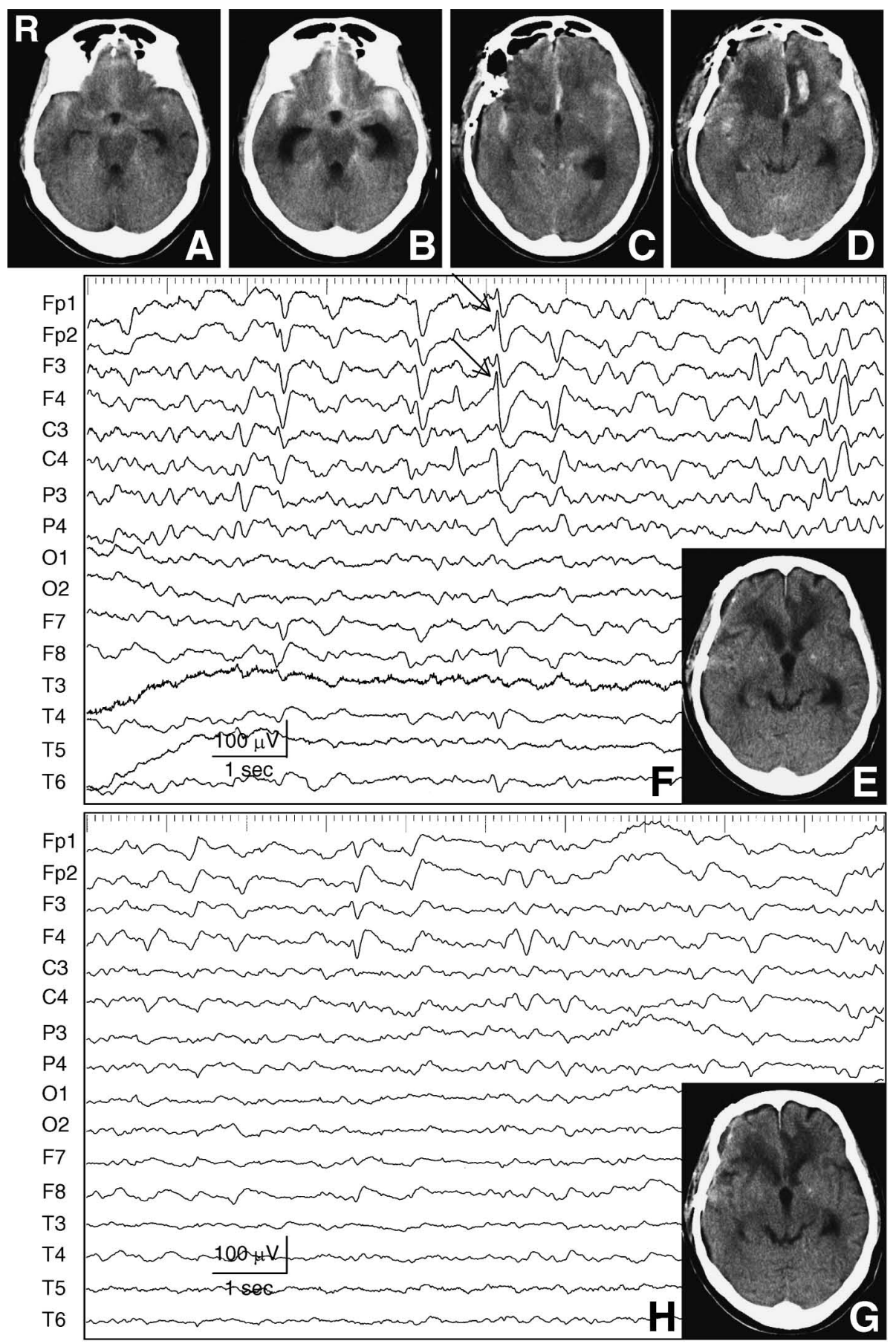

Fig. 2 Case 2. A: Computed tomography (CT) scan on day 0 revealing subarachnoid hemorrhage. B: CT scan on day 1 showing dense cisternal hemorrhage, indicating re-rupture of the aneurysm. C: Postoperative CT scan showing an equivocal low density area in the bilateral frontal base, predominantly on the right. D: CT scan on day 3 showing a low density area in the bilateral frontal lobes, and intracerebral hemorrhage in the left low density area. E: CT scan on day 20 revealing no additional abnormal findings. F: Electroencephalogram (EEG) $\left(A_{1} A_{2}\right.$ reference) on day 22 revealing triphasic waves in the bilateral frontal regions, predominantly on the right. Triphasic waves in the right frontal region exhibit "spike and slow wave" complex morphologies (arrows). G: CT scan after lumboperitoneal shunt under general sevoflurane anesthesia demonstrates well-controlled ventricular size. H: EEG on day 35 showing reappearance of triphasic waves in the bilateral frontal regions. 

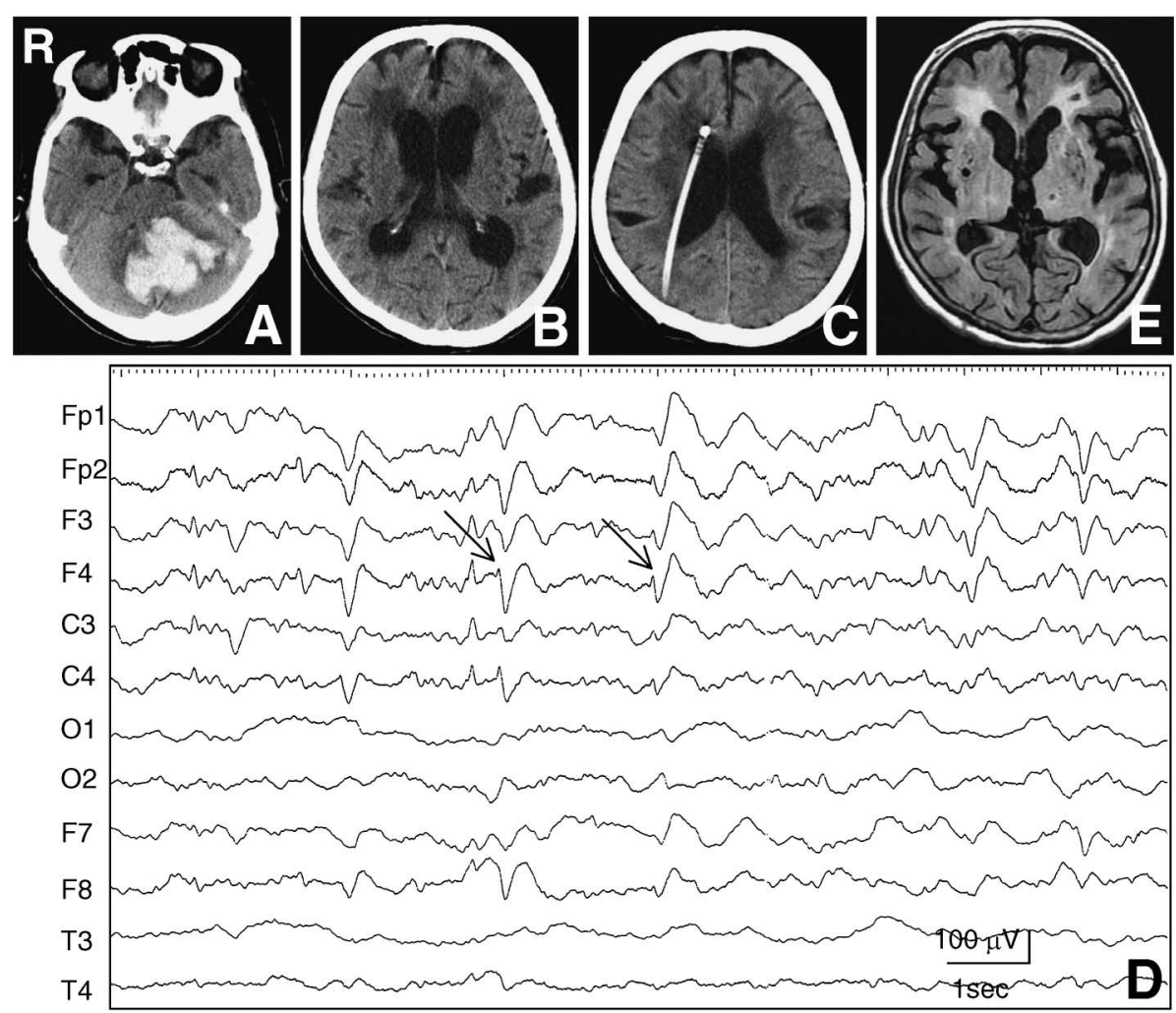

Fig. 3 Case 3. A, B: Computed tomography (CT) scans on day 0 revealing massive left cerebellar hemorrhage and obstructive hydrocephalus. C: Postoperative CT scan demonstrating well-controlled hydrocephalus. D: Electroencephalogram $\left(A_{1} A_{2}\right.$ reference) on day 5 showing triphasic waves in the bilateral frontal regions, predominantly on the right. The triphasic waves in the right frontal region have "spike and slow wave" complex morphologies (arrows). E: Fluid-attenuated inversion recovery magnetic resonance image demonstrating multiple old infarctions in the white matter of the bilateral frontal lobes, basal ganglia, and left thalamus.

Case 4: A 77-year-old man developed cerebral hyperperfusion syndrome with temporal deterioration of consciousness level and worsening of left hemiparesis on the 6th postoperative day following STA-MCA anastomosis for right MCA occlusion. This case was previously reported, ${ }^{13)}$ so only a brief description of the clinical course and long-term period observation is given. EEG revealed frequent ictal discharges (rhythmic slow waves originated from the right temporo-posterior region posterior to the anastomosis site) in the right hemisphere. With rapid improvement of EEG findings following phenytoin administration, complete recovery from hyperperfusion syndrome was achieved. At 11 months after surgery, the mRS value was 2 (unchanged from the pre-surgical state).

\section{Discussion}

The reported incidence of NCSE associated with CVD varies across studies. ${ }^{25)}$ NCSE was reported in $3-8 \%$ of patients with aneurysmal subarachnoid hemorrhage, ${ }^{23,24)}$ but no cases of NCSE were identified in 904 patients with CVD. ${ }^{22)}$ These contradictory results are probably due to heterogeneous definitions and diagnostic criteria of NCSE. Some reports originate from tertiary epilepsy centers or neuro-intensive care units (neuro-ICU), which have continuous EEG monitoring facilities, ${ }^{14)}$ whereas others are population-based. ${ }^{25,30}$ The present study demonstrated that as many as $7.4 \%$ of patients with CVD developed NCSE during the perioperative period, which would not have been detected without EEG analysis. This percentage is greater than expected, and the true percentage could be higher than $7.4 \%$.

In the present study, EEG was utilized, because patients with worse clinical symptoms than expected were suspected to have NCSE. In addition, some of the patients with expected neurological conditions could also have had NCSE. Poor neurological grade (Hunt and Hess grade III, IV, or V), thick cisternal blood clots, and structural lesions (intracerebral hemorrhage and stroke) are common in patients with subarachnoid hemorrhage associated 
with NCSE. ${ }^{23)}$ Some patients may also have had NCSE prior to EEG. Because our hospital does not have a neuro-ICU, EEG is often unavailable outside working hours or on weekends. Without continuous EEG monitoring, NCSE could be missed. ${ }^{18)}$ EEG is required to verify the diagnosis of NCSE, but a large number of EEG patterns have been described in NCSE. However, many of these are controversial, particularly as to any ictal character. ${ }^{4,20)}$ Patterns include PLEDs, bilateral independent PLEDs, periodic epileptiform discharges which can be either focal or generalized, and triphasic waves, ${ }^{4,20,21,25)}$ which have been standardized by a subcommittee of the American Clinical Neurophysiology Society. ${ }^{15)}$

Functional stratification of NCSE can be based on focal or generalized features of EEG, and clinical criteria have been proposed as follows: localizationrelated NCSE, generalized NCSE, and undetermined or intermediate NCSE. ${ }^{19)}$ The present 4 cases were localization-related NCSE based on the EEG and clinical criteria. Very few of the several hundreds of cases of NCSE were described with the pathophysiological mechanisms of epilepsy.

In Case 1, EEG revealed PLEDs, occurring as periodic complexes every 1-2 seconds that consisted of spikes or sharp waves followed by a slow wave. ${ }^{6)}$ PLEDs characteristically appear in a hemisphere containing an acute unilateral forebrain lesion, which most commonly occurs in patients with CVD. ${ }^{12,17,26)}$ Although PLEDs may occur in fully conscious patients with epilepsia partialis continua, as well as negative motor seizures that mimic transient ischemic attack, the comatose or confusion states associated with PLEDs are generally accepted to be caused by NCSE. ${ }^{2)}$ In Case 1, the location of the highest amplitude of PLEDs was identical to the intracerebral hematoma location. Therefore, this small hematoma was thought to be an epileptogenic lesion. The relationship between PLEDs and cerebral blood flow (CBF) and metabolism is well documented, ${ }^{17,26)}$ and blood flow changes have been shown to alter seizure threshold. ${ }^{12)}$ In addition, a reduction in threshold was found in patients who underwent CEA and developed seizures and PLEDs, which were ipsilateral to hyperperfusion-associated CEA. ${ }^{27)}$ In Case 1, the wide region of venous congestion around the small intracerebral hematoma was associated with dural AVF, which was very probably involved in the epileptogenesis.

In Cases 2 and 3, EEG demonstrated triphasic waves. The word "triphasic" has been used to describe a waveform characterized by an initial small amplitude sharp negative component, followed by a large amplitude sharp positive wave, and ending with a slow negative wave. ${ }^{1,3,10,20,21)}$ These findings were originally limited to patients with hepatic failure, so triphasic wave encephalopathy became synonymous with hepatic encephalopathy. Subsequently, triphasic wave encephalopathy has become associated with a wide range of toxic, metabolic, and structural abnormalities. ${ }^{1)}$ However, triphasic waves are now generally accepted as one of the EEG features in patients with NCSE, although the triphasic waves of NCSE are often difficult to distinguish from those of encephalopathy. ${ }^{4,21)}$

The distribution of triphasic waves is one of the differential points between NCSE and encephalopathy. The triphasic waves show asymmetry and predominantly focal location in NCSE, whereas the triphasic waves tend to be symmetric, anterior, and bilateral in encephalopathy. ${ }^{4,21)}$ In the present cases, although triphasic waves were located in the bilateral frontal regions, triphasic waves on the right exhibited larger amplitude and were extended more posteriorly. In addition, laboratory data found neither liver nor renal dysfunction. Furthermore, improved mental status and consciousness level, in conjunction with disappearance of the triphasic waves, following appropriate treatment with antiepileptic agents was supportive of the diagnosis of NCSE.

The triphasic wave associated with NCSE assumes a particular epileptiform morphology with prominent and distinctive first phases resembling spikes of "spike and slow wave" complexes. ${ }^{19)}$ In Case 2, the triphasic waves in the right frontal region exhibited such complex morphology, and we postulate that the acute infarction in the right frontal lobe, caused by intraoperative temporary occlusion of the dominant $A_{1}$, was the epileptogenic area. We also thought that subarachnoid clots, post-operative meningitis, and administration of carbapenem antibiotics for meningitis were additional factors in the development of NCSE.

In Case 2, NCSE recurrence was noted after placement of the LP shunt under general anesthesia with sevoflurane. The intracranial procedures were not performed during surgery, so the NCSE recurrence was probably due to the pharmacological effect of sevoflurane. The relationship between sevoflurane and intra- or peri-operative drug-induced seizure has been extensively investigated. ${ }^{33)} \mathrm{A}$ review of 30 studies which had investigated sevoflurane and epileptiform EEG changes and/or seizurelike movements in both epileptic patients and normal patients found that the incidence was very variable (0-100\%).7) According to the recommendations, hypocapnia should be avoided and the dose of sevoflurane limited to below 1.5 minimum alveolar anesthetic concentration during maintenance of 
anesthesia by use of adjunctive drugs (either opioids, benzodiazepines, or nitrous oxide) and routine EEG monitoring. However, inhalation of sevoflurane is often used during epilepsy surgery to induce epileptic activities on intraoperative electrocorticography and identify the epileptogenic area in patients with intractable epilepsy. ${ }^{11,16)}$ Therefore, sevoflurane anesthesia should be probably avoided in patients with preexisting epilepsies and intracranial pathologies that can induce symptomatic epilepsies.

In Case 3, triphasic waves in the right frontal region exhibited "spike and slow wave" complex morphology, unrelated to the right cerebellar hemorrhage. Although most cerebellar outputs inhibit epileptic seizure, ${ }^{5)}$ it is generally accepted that there is no relationship between cerebellar hemorrhage and epilepsy. In Case 3, the epileptogenic lesion was thought to be the old infarction in the right frontal region, which was affected by acute hydrocephalus and sevoflurane anesthesia.

In Case 4, delayed cerebral hyperperfusion syndrome developed at 6 days after STA-MCA anastomosis for right MCA occlusion. EEG demonstrated frequent ictal discharges, which originated from the right occipital region or temporo-occipital junction posterior to the anastomosis site that extended to the central and parietal region. Although whether seizures or delayed hyperperfusion were the initial phenomenon cannot be determined, hyperperfusion has been shown to be the major factor in NCSE development. ${ }^{13,27)}$

The possible pathophysiological mechanisms of NCSE in our 4 cases are summarized in Table 1 . The 4 patients presented with epileptogenic lesions and additional factors, so the development of perioperative NCSE was multifactorial. Venous congestion and hyperperfusion were the major pathophysiological mechanisms of NCSE in Cases 1 and 4, respectively. Since acute hydrocephalus and subsequent drainage was also associated with CBF change in Case 3, change in CBF may be the most important factor in the development of perioperative NCSE.

The mortality and morbidity are mainly dependent on the underlying etiology and age, but NCSE carries a poor prognosis, and prompt diagnosis and subsequent treatment is critical. ${ }^{2,9,14,18,21,25,29)}$ The first recommended treatment for NCSE is infusion of benzodiazepine agent, such as $5-10 \mathrm{mg}$ diazepam. ${ }^{21,25,29)}$ In particular, EEG should be continued in patients with triphasic waves to observe the effects of diazepam and to distinguish between NCSE and encephalopathy. ${ }^{21)}$ The second step is infusion of phenytoin or phenobarbital. ${ }^{21,25,29)}$ If prolonged seizure activity is noted, midazolam or propofol anesthesia may be indicated. ${ }^{21,25,29)}$ In the present study, venous phenytoin administration, rather than diazepam, was used as the first intervention in 2 cases. Diazepam depressed the consciousness level, ${ }^{19)}$ although the effects and role of diazepam in the diagnosis of NCSE remain under discussion. ${ }^{4)}$ Prophylactic administration of phenytoin was given in the other 2 cases, although no criteria are specified for postoperative administration of prophylactic antiepileptic agents in our hospital. The antiepileptic agents were changed from phenytoin to carbamazepine based on the diagnosis of localization-related NCSE. These prompt and appropriate antiepileptic agent treatments resulted in rapid improvement in clinical and EEG findings and better functional outcome in all patients.

No firm conclusion can be drawn from a 1-year study at a medium-sized, local hospital, but we found that NCSE was quite common (7.4\%) during the perioperative period of CVD surgery. EEG should be considered, even in the absence of seizures, if no adequate explanation for neurological deterioration can be established based on the clinical course, laboratory data, or neuroimaging findings.

\section{Acknowledgments}

We thank Drs. Toshio Higashi and Masahiro Takezawa, at the Department of Neurosurgery, Kokura Memorial Hospital (Kitakyushu, Fukuoka), for treating Case 1 with their skillful endovascular techniques.

\section{References}

1) Bahamon-Dussan JE, Celesia GG, Grigg-Damberger MM: Prognostic significance of EEG triphasic waves in patients with altered state of consciousness. J Clin Neurophysiol 6: 313-319, 1989

2) Bauer G, Trinka E: Nonconvulsive status epilepticus and coma. Epilepsia 51: 177-190, 2010

3) Bickford RG, Butt HR: Hepatic coma: the electroencephalographic pattern. J Clin Invest 34: 790-799, 1955

4) Brenner RP: EEG in convulsive and nonconvulsive status epilepticus. J Clin Neurophysiol 21: 319-331, 2004

5) Chae JH, Kim SK, Wang KC, Kim KJ, Hwang YS, Cho BK: Hemifacial seizure of cerebellar ganglioglioma origin: Seizure control by tumor resection. Epilepsia 42: 1204-1207, 2001

6) Chatrian GE, Show CM, Leffman H: The significance of periodic lateralized epileptiform discharges in EEG: An electrographic, clinical and pathological study. Electroencephalogr Clin Neurophysiol 17: 177-193, 1964 
7) Constant I, Seeman R, Murat I: Sevoflurane and epileptiform EEG changes. Paediatr Anaesth 15: 266-274, 2005

8) De Reuck J, Van Maele G: Status epilepticus in stroke patients. Eur Neurol 62: 171-175, 2009

9) Drislane FW: Evidence against permanent neurological damage from nonconvulsive status epilepticus. J Clin Neurophysiol 16: 323-331, 1999

10) Foley JM, Watson CW, Adams RD: Significance of the electroencephalographic changes in hepatic coma. Trans Am Neurol Assoc 75: 161-165, 1950

11) Fukui K, Morioka T, Hashiguchi K, Kawamura T, Irita K, Hoka S, Sasaki T, Takahashi S: Relationship between regional cerebral blood flow and electrocorticographic activities under sevoflurane and isoflurane anesthesia. J Clin Neurophysiol 27: 110-115, 2010

12) Garcia-Morales I, Garcia MT, Galan-Davila L, Gomez-Escalonilla C, Saiz-Diaz R, Martinez-Salio A, de la Pena P, Tejerina JA: Periodic lateralized epileptiform discharges. Etiology, clinical aspects, seizures, and evolution in 130 patients. J Clin Neurophysiol 19: 172-177, 2002

13) Hamamura $T$, Morioka $T$, Sayama $T$, Mukae $N$, Arakawa S, Maeda H, Sasaki T: Cerebral hyperperfusion syndrome associated with non-convulsive status epilepticus following superficial temporal arterymiddle cerebral artery anastomosis. Case report. Neurol Med Chir (Tokyo) 50: 1099-1104, 2010

14) Hirsch LJ: Continuous EEG monitoring in the intensive care unit: An overview. J Clin Neurophysiol 21: 332-340, 2004

15) Hirsch LJ, Brenner RP, Drislane FW, So E, Kaplan PW, Jordan KG, Herman ST, LaRoche SM, Young B, Bleck TP, Scheuer ML, Emerson RG: The ACNS subcommittee on research terminology for continuous EEG monitoring: Proposed standardized terminology for rhythmic and periodic EEG patterns encountered in critically ill patients. J Clin Neurophysiol 22: 128-135, 2005

16) Hisada K, Morioka T, Fukui K, Nishio S, Kuruma T, Irita K, Takahashi S, Fukui M: Effects of sevoflurane and isoflurane on electrocorticographic activities in patients with temporal lobe epilepsy. J Neurosurg Anesthesiol 13: 333-337, 2001

17) Hisada K, Morioka $T$, Nishio S, Muraishi $M$, Yamamoto T, Yoshida T, Fukui M: Magnetoencephalographic analysis of periodic lateralized epileptiform discharges (PLEDs). Clin Neurophysiol 111: 122-127, 2000

18) Jordan KG: Nonconvulsive status epilepticus in acute brain injury. J Clin Neurophysiol 16: 332-340, 1999

19) Kaplan PW: Assessing the outcomes in patients with nonconvulsive status epilepticus: nonconvulsive status epilepticus is underdiagnosed, potentially overtreated, and confounded by comorbidity. J Clin Neurophysiol 16: 341-352, 1999
20) Kaplan PW: The EEG in metabolic encephalopathy and coma. J Clin Neurophysiol 21: 307-318, 2004

21) Kaya D, Bingol CA: Significance of atypical triphasic waves for diagnosing nonconvulsive status epilepticus. Epilepsy Behav 11: 567-577, 2007

22) Labovitz DL, Hauser WA, Sacco RL: Prevalence and predictors of early seizure and status epilepticus after first stroke. Neurology 57: 200-206, 2001

23) Little AS, Kerrigan JF, McDougall CG, Zabramski JM, Albuquerque FC, Nakaji P, Spetzler R: Nonconvulsive status epilepticus in patients suffering spontaneous subarachnoid hemorrhage. J Neurosurg 106: 805-811, 2007

24) Lyle DJ, Claassen J, Lawrence HJ, Ronald EG, Sander CE, Stephan MA: Nonconvulsive status epilepticus after subarachnoid hemorrhage. Neurosurgery 51: 1136-1144, 2002

25) Meierkord H, Holtkamp M: Non-convulsive status epilepticus in adults: clinical forms and treatment. Lancet Neurol 6: 329-339, 2007

26) Pohlmann-Eden B, Hoch DB, Cochius JI, Chiappa KH: Periodic lateralized epileptiform discharges-a critical review. J Clin Neurophysiol 13: 519-530, 1996

27) Reigel MM, Hollier LH, Sundt TM, Piepgras DG, Sharbrough FW, Cherry KJ: Cerebral hyperperfusion syndrome: a cause of neurologic dysfunction after carotid endarterectomy. J Vasc Surg 5: 628-634, 1987

28) Rumbach L, Sablot D, Berger E, Tatu L, Vuillier F, Moulin T: Status epilepticus in stroke. Report on a hospital-based stroke cohort. Neurology 54: 350-354, 2000

29) Shah AM, Vashi A, Jagoda A: Review article: Convulsive and non-convulsive status epilepticus: An emergency medicine perspective. Emerg Med Australas 21: 352-366, 2009

30) Towne AR, Waterhouse EJ, Boggs JG, Garnett LK, Brown AJ, Smith JR Jr, DeLorenzo RJ: Prevalence of nonconvulsive status epilepticus in comatose patients. Neurology 54: 340-345, 2000

31) Van Swieten JC, Koudstaal PJ, Visser MC, Schouten $\mathrm{HJ}$, van Gijn J: Interobserver agreement for the assessment of handicap in stroke patients. Stroke 19: 604-607, 1988

32) Velioglu SK, Ozmenoglu M, Boz C, Alioglu Z: Status epilepticus after stroke. Stroke 31: 1169-1172, 2001

33) Voss LJ, Sleigh JW, Barnard JPM, Kirsch HE: The howling cortex: Seizures and general anesthetic drugs. Anesth Analg 107: 1689-1703, 2008

Address reprint requests to: Takato Morioka, MD, PhD, Department of Neurosurgery, Kyushu Rosai Hospital, 1-3-1 Kuzuharatakamatsu, Kokuraminami-ku, Kitakyushu, Fukuoka 800-0296, Japan. e-mail: takato@med.kyushu-u.ac.jp 